\title{
Rice Biofortification for Assessment of Hidden Hunger: A Review
}

\author{
Amit Pippal", Rajinder K. Jain and Sunita Jain \\ Department of Molecular Biology, Biotechnology and Bioinformatics, CCS Haryana \\ Agricultural University, Hisar-125004, Haryana, India \\ *Corresponding author
}

\begin{tabular}{|c|c|}
\hline & A B S T R A C T \\
\hline & Biofortification is an effective and economical method to improve the \\
\hline Keywords & in developing countries. Rice (Oryza sativa), one of the most important food crops \\
\hline $\begin{array}{l}\text { Rice, Biofortification, } \\
\text { Micronutrients. }\end{array}$ & $\begin{array}{l}\text { in the world, feeds more than half of the world's population and issued as a staple } \\
\text { food in many parts of Asia. Considered as a "model cereal crop" for genomic }\end{array}$ \\
\hline Article Info & $\begin{array}{l}\text { studies. Most of the staple foods including rice provide diets of low nutritional } \\
\text { quality including vitamins, essential amino acids, iron, zinc, iodine, etc. Iron and }\end{array}$ \\
\hline $\begin{array}{l}\text { Accepted: } \\
\text { 17 September } 2017 \\
\text { Available Online: } \\
\text { 10 November } 2017\end{array}$ & $\begin{array}{l}\text { zinc deficiencies are the two major factors for micronutrient malnutrition in the } \\
\text { world, affecting an estimated } 2 \text { billion people. A lot of variability does exist for } \\
\text { micronutrient (Fe, Zn, Vitamin } \mathrm{A} \text {, etc) content and bioavailability in many crops } \\
\text { including rice. Here, we briefly review the progress in biofortification of rice with }\end{array}$ \\
\hline & micronutrient elements $(\mathrm{Fe}$ and $\mathrm{Zn})$. \\
\hline
\end{tabular}

\section{Introduction}

Rice is the staple food for billions of people in Asia, Africa and Latin America. Estimated global area of rice is 164.7 million ha (FAO, 2013). Asia is major producer and consumer of rice accounting for $90-92 \%$ of world's rice area. In 2016-17, the global production of rice was 482 million tonnes; in India the production was 106.5 million tonnes (USDA, 2017). India stands first in terms of area under cultivation and second in rice production after China. Rice (Oryza sativa L.) has become a model plant species for genomic research because of its small genome size ( 430 million bp). Rice is a source of dietary energy, protein, vitamins and essential fatty acid and micronutrients for poor and vulnerable society that relied upon it as a staple food. In developing countries, Asia, Africa and Latin America, per capita consumption of rice is very high accounting to 483 million tonnes in 2015-16 (USDA, 2016). The micronutrient malnutrition associated health risks have become a major hindrance in achieving the Millennium Development Goals (MDG) such as reducing poverty and hunger, improved maternal health status and less child mortality and these are also important sustainable development goals (SDGs) to be achieved by 2035.

\section{Micronutrient deficiency/malnutrition}

Micronutrient deficiency is the lack of essential vitamins and minerals needed in 
small amounts to support physiological functions that must be provided in food or as supplements because they cannot be made by the body in sufficient amounts to meet daily needs. Micronutrients are required in small amounts by the body for proper growth and development. Marginal intakes of micronutrients have been shown to contribute to increased morbidity and mortality rates, diminished livelihood and adverse effects on learning ability, development and growth in infants and children. Fe and $\mathrm{Zn}$ deficiencies are among the most prevalent micronutrient deficiencies in humans, affecting two billion people and causing more than 0.8 million deaths annually (World Health Organization, 2013). Nearly two-thirds of all deaths of children are associated with nutritional deficiencies; many from micronutrient deficiencies (Caballero, 2002).

Micronutrient deficiencies or "hidden hunger" affect about $38 \%$ of pregnant women and $43 \%$ of preschool children worldwide and are most prevalent in developing countries. Even mild levels of micronutrient malnutrition may damage cognitive development, lower disease resistance in children and reduce the likelihood that mothers survive child birth. It is important to identify who the malnourished are, where they are located and what they eat in order to develop an effective strategy to reduce micronutrient malnutrition.

\section{Iron deficiency}

Iron deficiency is one of the most prevalent micronutrient deficiencies, affecting around two billion people globally (WHO, 2016). Children and women in the developing countries are particularly vulnerable with 300 million children and more than 500 million women suffering from iron deficiency anemia worldwide (WHO, 2015).Global studies estimate that approximately half of this is due to iron-deficiency anemia (IDA) (Brotanek et al., 2005). IDA can affect productivity and cause serious health consequences including impaired cognitive development in children, a weakened immune system and increased risk of morbidity (Black et al., 2003). Recently, low maternal Fe intake has been linked to autism spectrum disorder in their offspring (Schmidt et al., 2014). Nutritional studies suggested that $24-28 \mathrm{mg} \mathrm{kg}^{-1} \mathrm{Zn}$ and $13 \mathrm{mg}$ $\mathrm{kg}^{-1} \mathrm{Fe}$ concentration in polished grain is essential to reach the $30 \%$ of human estimated average requirement (Bouis et al., 2011).

\section{Zinc deficiency}

One third of the world population is at risk due to low dietary intake of $\mathrm{Zn}$ (Hotz and Brown, 2004; Myers et al., 2015) including 2 billion people in Asia and 400 million in subSaharan Africa (Institute, 2006). Zinc deficiency is a major cause of stunting among children (Brown et al., 2000). About 165 million children with stunted growth run a risk of compromised cognitive development and physical capability (Black et al., 2013 and Wessells et al., 2012). More than $85 \%$ of total body zinc is found in skeletal muscles and bones (King, 2000). The recommended dietary allowances for $\mathrm{Zn}$ are $5 \mathrm{mg}$ /day for infants, $10 \mathrm{mg} /$ day for children less than 10 years, $15 \mathrm{mg} /$ day for males more than 10 years, $12 \mathrm{mg} /$ day for females more than 10 years and $15 \mathrm{mg} /$ day for women during pregnancy (Welch, 2001). Zinc deficiency is responsible for the development of a large number of illness and diseases including stunting of growth, compromised immune system function (Prasad, 2009; Barnett et al., 2010), cancer (Hotz and Brown, 2004), susceptibility to infectious diseases and poor birth outcomes in pregnant women (Prasad, 2009; Graham et al., 2012), hair and memory loss, skin problems, weakening of body muscles, infertility in men and pneumonia in children (Stein et al., 2005; Das and Green, 2013). 


\section{Strategies for mineral uptake in plants}

Higher plants use two major iron uptake strategies under conditions of low iron supply based on: reduction (strategy I) and chelation (strategy II) (Graham and Stangoulis, 2003; Grotz and Guerinot, 2006).

\section{Reduction (Strategy I)}

Strategy I, which is used by dicotyledons and non-graminaceous plant species, lower the soil $\mathrm{pH}$ by excretion of protons into the rhizosphere, then ferric-chelate reductase (FRO) reduces Fe to more soluble ferrous ion at the root surface and finally transport the resulting $\mathrm{Fe}^{2+}$ across the root plasma membrane through iron-regulated transporterlike protein 1 (IRT1) (Cakmak et al., 1996; Vert et al., 2002). In Arabidopsis, this is encoded by the AtFRO2 gene (Guerinot and $\mathrm{Yi}$, 1994). The expression of AtFRO3 is strongly induced upon $\mathrm{Fe}$ deficiency, which suggests that the latter gene has a similar function (Wu et al., 2005). Ishimaru et al., (2007) introduced a yeast ferric chelate reductase gene into rice and observed increase in iron uptake ability. They reported an impressive 7.9-fold increase in grain yield for transgenic rice plants when grown in calcareous soil.

\section{Chelation (Strategy II)}

Strategy II is used by graminaceous plants, involving the secretion of small molecules called mugineic acid family phytosiderophores (MAs) that bind to and solubilize Fe (III) (Takagi, 1976; Takagi et al., 1984), and the resulting $\mathrm{Fe}(\mathrm{III})-\mathrm{MA}$ complexes are readily taken up by the yellow stripe-like (YSL) family of transporters at the root surface (Curie et al., 2001). NA synthase (NAS) converts three molecules of Sadenosyl methionine (SAM) to NA, which is then converted to a $3^{\prime}$-keto intermediate by
NA aminotransferase (NAAT). This 3'-keto intermediate is then reduced to produce deoxymugineic acid (DMA) by the action of DMA synthase (DMAS) (Bashir and Nishizawa, 2006; Bashir et al., 2006). This DMA is then released into the rhizosphere through transporter of MAs1. Rice and maize secrete only DMA, while other species including barley and rye, further hydroxylate DMA to other MAs. The biosynthesis and secretion of MAs increase substantially in roots in response to iron deficiency (Takagi, 1976; Takagi et al., 1984). The tolerance to iron deficiency among graminaceous plants is thought to be dependent on the amounts secretion of MAs. Nicotianamine, an intermediate of MAs biosynthesis, is a structural analogue of MA that chelates metal cations, including $\mathrm{Fe}$ and other metals such as zinc, manganese $(\mathrm{Mn})$ and copper $(\mathrm{Cu})$ (Benes et al., 1983).

Although the molecular mechanisms for $\mathrm{Zn}$ uptake are not completely understood, it has been suggested that plants may also use Strategy II to obtain $\mathrm{Zn}$ from soil. Graminaceous plant species respond to $\mathrm{Fe}$ and $\mathrm{Zn}$ deficiency by exudation of phytosiderophores (PSs), increasing the availability of these metals. Thus, $\mathrm{PS}-\mathrm{Fe}^{3+}$ or $\mathrm{PS}-\mathrm{Zn}^{2+}$ complexes are transported from the rhizosphere to the root for uptake. The MAs family plays a major role in $\mathrm{Fe}$ acquisition and contributes to the acquisition of $\mathrm{Zn}$ by these plants. Although, the IRT transporter has been established as the major Fe uptake system from the soil, IRT is also responsible for uptake of $\mathrm{Zn}$. Genetic engineering approaches have been applied for increasing plant tolerance to low-Zn soils. For example, over expression of known $\mathrm{Zn}$ transporters from Arabidopsis to barley can increase the plant $\mathrm{Zn}$ uptake and seed $\mathrm{Zn}$ content. These results show the contribution of molecular genetics tools to manipulate $\mathrm{Zn}$ and $\mathrm{Fe}$ efficiency in crops and the potential for 
enrichment of the food supply with these metals (Vert et al., 2002; Zuo and Zhang, 2008).

\section{Biofortification}

Biofortification (increasing the contents of vitamins and micronutrients through plant breeding or biotechnology) of food crops with vitamins and micronutrients is not a new concept and was suggested more than a decade ago as a way to significantly ameliorate deficiencies in major food crops (Ye et al., 2000; Guerinot, 2001). This approach will not only lower the number of severely malnourished people who require treatment by complementary interventions, but also help them in maintaining improved nutritional status. Moreover, biofortification provides a feasible means of reaching malnourished rural populations who may have limited access to commercially marketed fortified foods and supplements.

In humans, cereals are the most important source of calories. Rice, wheat and maize provide about 23\%, $17 \%$ and $10 \%$, respectively, of the calories acquired globally (Khush, 2003). To effectively target biofortification of cereals, five key steps can be: (i) enhanced uptake from soil (ii) increased transport of micronutrients to grains (iii) Increased sequestration of minerals to endosperm rather than husk and aleurone (iv) reduction in anti-nutritional factors in grains (v) increase in promoters of mineral bioavailability in grains. Major advantages of biofortification are:

\section{Reaching the malnourished in rural areas}

The biofortification strategy seeks to put the micronutrient-dense trait in the most profitable, highest-yielding varieties targeted to farmers and to place these traits in as many released varieties as is feasible. Moreover, marketed surplus of these crops make their way into retail outlets, reaching consumers in both rural and urban areas.

\section{Cost-effectiveness and low cost}

After one-time investment is made to develop seeds that fortify themselves, recurrent costs are low and germplasm may be shared internationally. It is this multiplier aspect of plant breeding across time and distance that makes it so cost-effective.

\section{Behavioral change}

Mineral micronutrients make up a tiny fraction of the physical mass of a seed, 5-10 parts per million in milled rice. Dense bean seeds may contain as many as 100 parts per million. Whether such small amounts will alter the appearance, taste, texture or cooking quality of foods is needed to investigate. If increased densities in iron and zinc are not noticeable by consumers, the dissemination strategy for trace minerals could rely on existing producer and consumer behavior.

\section{Sustainability of biofortification}

The biofortified crop system is highly sustainable. Nutritionally improved varieties will continue to grow and consumed year after year, even if government attention and international funding for micronutrient issue fades.

\section{Variation and breeding for mineral content in rice}

In rice seed, $\mathrm{Fe}$ localizes to dorsal vascular bundle, aleurone layer and endosperm as well as it localizes to the scutellum and vascular bundle of the scutellum of embryo. During germination localization of iron changes significantly, particularly in embryo and $36 \mathrm{~h}$ after sowing, iron localizes to the scutellum, 
coleoptiles and epithelium, as well as to the leaf primordium and radical (Takahashi et al., 2009). Most of the Zinc in seed is located in the embryo and aleurone layer, whereas the endosperm is very low in Zinc concentration. Unlike iron, zinc is unevenly distributed to all of parts of the seed with a significantly high value for the aleurone layer and embryo (Takahashi et al., 2009). Rice breeders are expected to concentrate on increasing the total nutrient content in the endosperm of the grain, the part that remains after milling. The range of iron and zinc concentration in brown rice is 6.3-24.4 $\mu \mathrm{g} / \mathrm{g}$ and 13.5-28.4 $\mu \mathrm{g} / \mathrm{g}$ respectively. There was approximately four fold difference in iron and zinc concentration, suggesting vast genetic potential to increase the concentration of these micronutrients in rice grains (Gregorio, 2002). Over the last decade, several efforts have been made to biofortify food crops with micronutrients, which led to a significant understanding of the physiological, genetic and molecular basis of high iron and Zinc accumulation in grains, and also the influence of agronomic management and environmental factors on iron and Zinc uptake, translocation and loading into grains.

Brar et al., (2011) evaluated iron and zinc contents in 220 rice genotypes and they reported that iron and zinc contents of dehusked grains differed significantly. It ranged between $5.1-441.5 \mu \mathrm{g} / \mathrm{g}$ for iron and $2.12-39.4 \mu \mathrm{g} / \mathrm{g}$ for zinc. Of 220 rice genotypes evaluated, two genotypes; Taraori Basmati and Palman 579 had high iron $(>180 \mu \mathrm{g} / \mathrm{g})$ and zinc $(>25 \mu \mathrm{g} / \mathrm{g})$ content.

Anuradha et al., (2012a) analyzed brown rice of 126 accessions including cultivated indica and japonica rice cultivars, germplasm accessions and wild rice genotypes for $\mathrm{Fe}$ and $\mathrm{Zn}$ concentration in brown rice. $\mathrm{Fe}$ concentration ranged from $6.2 \mathrm{ppm}$ to 71.6 ppm and $\mathrm{Zn}$ concentration ranged from 26.2 ppm to $67.3 \mathrm{ppm}$. Both Fe and $\mathrm{Zn}$ were high in wild rice genotypes and least in japonica. The mean value of $\mathrm{Fe}$ concentration in all wild varieties was $27.5 \mathrm{ppm}$ ranging from $11.9 \mathrm{ppm}$ in SL-12 to $71.5 \mathrm{ppm}$ in SL-32. The mean value of $\mathrm{Zn}$ concentration in all wild accessions was 50.7 ppm ranging from 31.7 ppm in SL-12 to $67.2 \mathrm{ppm}$ in SL-48. The highest concentration in cultivars was 14.8 ppm for $\mathrm{Fe}$ and $39.4 \mathrm{ppm}$ for $\mathrm{Zn}$. The Fe concentration in cultivated varieties ranged from $6.6 \mathrm{ppm}$ in Athira to $48.3 \mathrm{ppm}$ in Annada and $\mathrm{Zn}$ concentration ranged from $25.1 \mathrm{ppm}$ in Jaya to $62.7 \mathrm{ppm}$ in Norungan. Out of 126 accessions only 8 lines had $>30$ ppm Fe and 12 lines had >50 ppm Zn. When 8 high Fe lines were analysed for $\mathrm{Zn}$, it was found that these lines also had high $\mathrm{Zn}(>30$ ppm). On the other hand when 8 high $\mathrm{Zn}$ lines were analysed for Fe, only three lines Swarna, SL-32 and SL-18 had high Fe (>25ppm).

Roy and Sharma (2014) analysed iron (Fe) and zinc $(\mathrm{Zn})$ content of rice landraces (84 cultivars) which were collected from various agro-ecological regions of West Bengal and adjoining areas. Iron and zinc concentration varied from $0.25 \mu \mathrm{g} / \mathrm{g}$ to $34.8 \mu \mathrm{g} / \mathrm{g}$ and 0.85 $\mu \mathrm{g} / \mathrm{g}$ to $195.3 \mu \mathrm{g} / \mathrm{g}$, respectively. While 'Swetonunia' had the highest iron $(34.8 \mu \mathrm{g} / \mathrm{g})$ and highest amount of $\mathrm{Zn}(195.3 \mu \mathrm{g} / \mathrm{g})$ was found in 'Nepali Kalam'.

Identification of micronutrient-rich genotypes opens up the possibilities for the linkage mapping of genomic regions or QTLs responsible for mineral uptake and translocation, which can be subsequently used as donor for developing nutrient enriched varieties.

\section{Transgenic strategies for improving} mineral content in rice

Transgenic efforts to increase the $\mathrm{Fe}$ concentration of rice endosperm include 
expression of ferritin genes, nicotianamine synthase genes (NAS) or ferritin in conjunction with NAS genes, with results ranging from two-fold increase via singlegene approaches to six-fold increase via multi-gene approaches. Fe storage capacity of rice grains through expression of the $\mathrm{Fe}$ storage protein ferritin under the control of endosperm-specific promoters. Using this approach, the concentration of Fe in the seeds of transformants was increased by approximately 2 -fold in polished seeds. Iron stored in ferritin is an important source for humans to avoid iron deficiency.

Goto et al., (1999) generated transgenic rice plants expressing the soybean ferritin gene SoyferH1 in endosperm using the rice endosperm-specific, $\quad 1.3-\mathrm{kb} \quad$ OsGluB1 promoter. Transformants showed 3-fold higher levels of $\mathrm{Fe}$ accumulation in brown seeds. Additionally, the concentration of iron in the endosperm was increased to 2-fold. This endosperm-specific expression of ferritin has been used to increase iron concentration in rice plants. These results suggested that increasing the soil $\mathrm{Fe}$ uptake and $\mathrm{Fe}$ translocation have the potential to further increase the $\mathrm{Fe}$ content of rice endosperm.

Lucca et al., (2001) exposed three distinct approaches for increasing the amount of iron absorbed from rice. To increase a ferritin gene from Phaseolus vulgaris into rice grains, iron content can be increase to two-fold. To increase iron bioavailability, a thermo tolerant phytase was introduced from Aspergillus fumigatus into the rice endosperm. In addition, as cysteine peptides are considered a major enhancer of iron absorption, for over expression of the endogenous cysteine-rich metallothionein-like protein. The content of cysteine residues increased to seven-fold and the phytase level in the grains was increased to 130-fold.There by giving a phytase activity. High phytase rice with increased iron content and rich in cysteine peptide has the potential to greatly improve iron nutrition in rice-eating populations.

Takahashi (2003) reported the development of transgenic rice plants expressing the barley nicotinamine aminotransferase (NAAT) gene, one of the genes of enzymes of MA biosynthetic pathway, which showed tolerance to low-Fe availability in calcareous soils. This phenomenon occurred because transgenic rice plants secreted higher amounts of MAs characteristic of strategy II than nontransgenic rice plants.

Iron deficiency in calcareous soil in transgenic rice plants containing yeast $\mathrm{Fe}^{3+}$ chelate-reductase gene (refre1/372) fused with the promoter of the Fe-regulated transporter, OSIRT1. Transgenic rice plants expressing the refre 1/372 gene showed higher $\mathrm{Fe}^{3+}$ chelate-reductase activity and a higher Fe-uptake rate than vector controls under Fedeficient conditions. Consequently, transgenic rice plants exhibited an enhanced tolerance to low-Fe availability and a 7.9 fold increase in the grain yield compared to the nontransformed plants in calcareous soils.

\section{Linkage mapping and molecular breeding for mineral content in rice}

Molecular markers are a valuable tool to identify and quantify genetic diversity within and between species, population and available germplasm. These genetic resources can also link genotypes with economically important traits and assist breeders with germplasm selection and potential crossing schemes (Gupta and Varshney, 2000).

Developing micronutrient-enriched staple plant foods, either through traditional plant breeding or via molecular biology techniques are the powerful intervention tools that targets the most vulnerable people (resource-poor 
women, infants and children) (Bouis, 2000). In plant breeding approach, high micronutrient trait can be combined with high yielding traits.

\section{Breeding Criteria}

Substantial, useful genetic variation in nutrient content exists in key staple crops.

Breeding programs can readily manage nutritional quality traits, which for some crops are highly heritable and simple to screen.

Desired traits are sufficiently stable across a wide range of growing environments.

Traits for high nutrient content can be combined with superior agronomic characteristics and high yields.

Kumar et al., (2014) observed that $\mathrm{F}_{2}$ population derived from the cross between high-yielding (PAU201) and iron-rich (Palman 579) indica rice varieties displayed large variation for various physiomorphological traits including iron and zinc contents. Transgressive segregation for grain iron and/or zinc content was noticed in some $\mathrm{F}_{2}$ individuals with one of the $\mathrm{F}_{2}$ plants having exceptionally higher iron $(475.4 \mu \mathrm{g} / \mathrm{g})$ as well as zinc $(157.4 \mu \mathrm{g} / \mathrm{g})$ content. Grain iron content showed significant positive correlation $(r=0.523)$ with grain zinc content indicating the feasibility of improving iron and zinc levels simultaneously in rice grain. SSR primers were used to map the QTL associated with mineral content in grains resulting total of eleven putative QTL for mineral content in rice grains on chromosomes 2, 3, 7, 10 and 12 were identified.

Brar et al., (2015) studied allele size of microsatellites associated with agronomic traits and mineral content based on 48 molecular markers in fourteen rice genotypes (Basmati, japonica and indica). There was significant correlation for 37 of 432 pairs among these markers and agronomic traits, as well as mineral traits. There was a significant correlation for 13of 96 pairs between allele size of molecular markers and mineral traits, 10 of 144 pairs between molecular markers and plant traits, 9 of 96 pairs between molecular markers and panicle traits and 5of 96 pairs between molecular markers and grain traits. Out of 48 molecular markers, ten were significantly correlated and associated with micronutrient (iron and zinc) traits and two with aromatic trait.

Swamy et al., (2016) identified 26 QTL from eight different mapping populations. It is clearly evident that genes/QTL for high grain $\mathrm{Zn}$ are distributed throughout the genome and also found to co-locate with QTL for other mineral elements in the grain. The number of QTL on each chromosome varied from 1 to 6 . One QTL each on chromosomes 1, 3, 8, 9, 10 and 11, two QTL each on chromosomes 2, 4 and 6, three QTL on chromosome 5, five and six QTL on chromosome 12 and 7 respectively. QTL on chromosomes 7 and 12 were found to be more consistent across the genetic backgrounds and environments. They consistently identified grain Zn QTLs on chromosomes 7,11 and 12 as good targets for MAS. Thus, it was possible to increase the grain $\mathrm{Zn}$ concentration by 10 to $15 \mathrm{ppm}$ in the existing popular rice varieties by a well designed Marker Assisted QTL pyramiding program.

\section{References}

Anuradha, K., Agarwal, S., Batchu, A.K., Babu, A.P., Swamy, B.M., Longvah, T. and Sarla, N. 2012a. Evaluating rice germplasm for iron and zinc concentration in brown rice and seed dimensions. Journal of Phytology, 4(1): 
19-25.

Barnett, J.B., Hamer, D.H. and Meydani, S.N. 2010. Low zinc status: a new risk factor for pneumonia in the elderly? Nutrition reviews, 68(1): 30-37.

Bashir, K. and Nishizawa, N.K. 2006. Deoxymugineic acid synthase: a gene important for Fe-acquisition and homeostasis. Plant signaling and behavior, 1(6): 290-292.

Bashir, K., Inoue, H., Nagasaka, S., Takahashi, M., Nakanishi, H., Mori, S. and Nishizawa, N.K. 2006. Cloning and characterization of deoxymugineic acid synthase genes from graminaceous plants. Journal of Biological Chemistry, 281(43): 32395-32402.

Beneš, I., Schreiber, K., Ripperger, H. and Kircheiss, A. 1983. Metal complex formation by nicotianamine, a possible phytosiderophore. Cellular and Molecular Life Sciences, 39(3): 261262.

Black, R., 2003. Micronutrient deficiency: an underlying cause of morbidity and mortality. Bulletin of the World Health Organization, 81(2): 79.

Black, R.E., Victora, C.G., Walker, S.P., Bhutta, Z.A., Christian, P., De Onis, M., Ezzati, M., Grantham-McGregor, S., Katz, J., Martorell, R. and Uauy, R. 2013. Maternal and child under nutrition and overweight in low income and middle-income countries. The lancet, 382(9890): 427-451.

Bouis, H.E. 2000. Enrichment of food staples through plant breeding: a new strategy for fighting micronutrient malnutrition. Nutrition, 16: 701-704.

Bouis, H.E., Hotz, C., McClafferty, B., Meenakshi, J.V. and Pfeiffer, W.H. 2011. Biofortification: a new tool to reduce micronutrient malnutrition. Food and nutrition bulletin, 32: 31-40.

Brar, B., Jain, S., Singh, R. and Jain, R.K. 2011. Genetic diversity for iron and zinc contents in a collection of 220 rice (Oryza sativa L.) genotypes. Indian Journal of Genetics and Plant Breeding, 71(1): 67-73.

Brar, B., Jaina, R.K. and Jain, S. 2015. Correlation of molecular marker allele size with physio-morphological and micronutrient $(\mathrm{Zn}, \mathrm{Fe})$ traits among rice genotypes. International Journal of Current Science, 15: 42-50.

Brotanek, J.M., Halterman, J.S., Auinger, P., Flores, G. and Weitzman, M. 2005. Iron deficiency, prolonged bottle-feeding, and racial/ethnic disparities in young children. Archives of pediatrics and adolescent medicine 159(11): 10381042.

Brown, K.H., Rivera, J.A., Bhutta, Z., Gibson, R.S., King, J.C., Lonnerdal, B., Ruel, M.T., Sandtröm, B., Wasantwisut, E., Hotz, C. and Lopez de Romaña, D. 2004. International Zinc Nutrition Consultative Group (IZiNCG) technical document 1. Assessment of the risk of zinc deficiency in populations and options for its control. Food and nutrition bulletin, 25: 2 .

Caballero, B. 2002.Global patterns of child health: the role of nutrition. Annals of Nutrition and Metabolism, 46: 3-7.

Cakmak, I.,Torun, B., Erenoğlu, B., Öztürk, L., Marschner, H., Kalayci, M., Ekiz, H. and Yilmaz, A. 1996. Morphological and physiological differences in the response of cereals to zinc deficiency. Euphytica, 100(1): 349-357.

Curie, C., Panaviene, Z., Loulergue, C., Dellaporta, S.L., Briat, J.F. and Walker, E.L. 2001. Maize yellow stripe1 encodes a membrane protein directly involved in $\mathrm{Fe}$ (III) uptake. Nature, 409(6818): 346-349.

Das, S. and Green, A. 2013. Importance of zinc in crops and human health. Journal of SAT Agricultural Research, 11: 1-7.

FAO. 2013. The state of food insecurity in the 
world.

Goto, F., Yoshihara, T., Shigemoto, N., Toki, S. and Takaiwa, F. 1999. Iron fortification of rice seed by the soybean ferritin gene. Nature biotechnology, 17(3): 282-286.

Graham, R.D. and Stangoulis, J.C. 2003. Trace element uptake and distribution in plants. The Journal of nutrition, 133(5): 1502-1505

Graham, R.D., Knez, M. and Welch, R.M. 2012. How Much Nutritional Iron Deficiency in Humans Globally Is due to an Underlying Zinc Deficiency? Advances in Agronomy, 115(1).

Gregorio, G.B., Senadhira, D. and Htut, T. and Graham, R.D. 1999. Improving iron and zinc value of rice for human nutrition. Agriculture development, 23(9): 68-87.

Grotz, N. and Guerinot, M.L.2006. Molecular aspects of $\mathrm{Cu}, \mathrm{Fe}$ and $\mathrm{Zn}$ homeostasis in plants. Molecular Cell Research, 1763(7): 595-608.

Guerinot, M.L. 2001. Improving rice yieldsironing out the details. Nature biotechnology, 19(5): 417-419.

Guerinot, M.L. and Yi, Y. 1994. Iron: nutritious, noxious, and not readily available. Plant Physiology, 104(3): 815.

Gupta, P.K. and Varshney, R.K. 2000. The development and use of microsatellite markers for genetic analysis and plant breeding with emphasis on bread wheat. Euphytica, 113(3):163-185.

Hotz, C. and Brown, K.H. 2004.Assessment of the risk of zinc deficiency in populations and options for its control. Food Nutrition Bulletin, 25(1):194-195.

Institute, I.R.R. 2006. Bringing Hope, Improving Lives: Strategic Plan 20072015. Manila: International Rice Research Institute.

Khush, G. 2003. Productivity improvements in rice. Nutrition reviews, 61(6):114-
116.

King, J.C. 2000. Determinants of maternal zinc status during pregnancy. The American journal of clinical nutrition, 71(5): 1334-1343.

Kumar, J., Jain, S. and Jain, R.K. 2014. Linkage mapping for grain iron and zinc content in $\mathrm{F}_{2}$ population derived from the cross between PAU201 and Palman 579 in rice (Oryza sativa L.). Cereal Research Communications, 42(3): 389400.

Lucca, P., Hurrell, R. and Potrykus, I. 2001. Genetic engineering approaches to improve the bioavailability and the level of iron in rice grains. Theoretical and Applied Genetics, 102(2): 392-397.

Myers, S.S., Wessells, K.R., Kloog, I., Zanobetti, A. and Schwartz, J. 2015. Effect of increased concentrations of atmospheric carbon dioxide on the global threat of zinc deficiency: a modelling study. The Lancet Global Health, 3(10): 639-645.

Prasad, A.S. 2009. Impact of the discovery of human zinc deficiency on health. Journal of the American College of Nutrition, 28(3): 257-265.

Roy, S.C. and Sharma, B.D. 2014. Assessment of genetic diversity in rice [Oryza sativa L.] germplasm based on agro-morphology traits and zinc-iron content for crop improvement. Physiology and Molecular Biology of Plants, 20(2): 209-224.

Schmidt, R.J., Tancredi, D.J., Krakowiak, P., Hansen, R.L. and Ozonoff, S. 2014. Maternal intake of supplemental iron and risk of autism spectrum disorder. American journal of epidemiology, 180(9): 890-900.

Stein, A.J., Meenakshi, J.V., Qaim, M., Nestel, P., Sachdev, H.P.S. and Bhutta, Z.A. 2005. Analyzing the Health Benefits of Biofortified Staple Crops by Means of the Disability-Adjusted Life 
Years Approach: a Handbook Focusing on Iron, Zinc and Vitamin A. Washington, DC: International Food, Policy Research Institute.

Swamy, B.M., Rahman, M.A., InabanganAsilo, M.A., Amparado, A., Manito, C., Chadha-Mohanty, P., Reinke, R. and Slamet-Loedin, I.H. 2016. Advances in breeding for high grain Zinc in Rice. Rice, 9(1): 49.

Takagi, S.I. 1976. Naturally occurring ironchelating compounds in oat-and riceroot washings: I. Activity measurement and preliminary characterization. Soil science and plant nutrition, 22(4): 423 433.

Takagi, S.I., Nomoto, K. and Takemoto, T. 1984. Physiological aspect of mugineic acid, a possible phytosiderophore of graminaceous plants. Journal of Plant Nutrition, 7(1-5): 469-477.

Takahashi, M. 2003.Overcoming Fe deficiency by a transgenic approach in rice. Plant cell, tissue and organ culture, 72(3): 211-220.

USDA, 2016.United States Department of Agriculture.

Vert, G., Grotz, N., Dédaldéchamp, F., Gaymard, F., Guerinot, M.L., Briat, J.F. and Curie, C. 2002. IRT1, an Arabidopsis transporter essential for iron uptake from the soil and for plant growth. The Plant Cell, 14(6): 12231233.

Welch, R.M., 2001. Micronutrients, agriculture and nutrition; linkages for improved health and well being. Perspectives on the micronutrient nutrition of crops. Jodhpur, India: Scientific Publishers: 247-289.

Wessells, K.R. and Brown, K.H. 2012. Estimating the global prevalence of zinc deficiency: results based on zinc availability in national food supplies and the prevalence of stunting. PloS one, 7(11): 50568.

WHO. 2013. World Health Organization.

WHO. 2015. World Health Organization.

WHO. 2016. World Health Organization.

Ye, X., Al-Babili, S., Klöti, A., Zhang, J., Lucca, P., Beyer, P. and Potrykus, I. 2000 . Engineering the provitamin A ( $\beta$ carotene) biosynthetic pathway into (carotenoid-free) rice endosperm. Science, 287(5451): 303-305.

Zuo, Y. and Zhang, F. 2008. Effect of peanut mixed cropping with gramineous species on micronutrient concentrations and iron chlorosis of peanut plants grown in a calcareous soil. Plant and Soil, 306(2): 23-36.

\section{How to cite this article:}

Amit Pippal, Rajinder K. Jain and Sunita Jain. 2017. Rice Biofortification for Assessment of Hidden Hunger: A Review. Int.J.Curr.Microbiol.App.Sci. 6(11): 2234-2243. doi: https://doi.org/10.20546/ijcmas.2017.611.265 